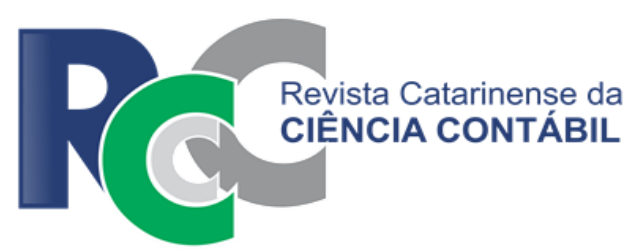

\title{
CORRUPÇÃO E VALOR DE MERCADO: OS EFEITOS DA OPERAÇÃO LAVA JATO SOBRE O MERCADO DE AÇÕES NO BRASIL
}

\author{
CORRUPTION AND MARKET VALUE: EFFECTS OF THE LAVA JATO OPERATION \\ ON THE BRAZILIAN STOCK MARKET
}

\author{
EDUARDO CARVALHO CORREA DE ARAÚJO \\ Mestre em Ciências Contábeis. Fucape Business School. Endereço: \\ Rua da Assembleia, 100, 3 Andar / Centro / Rio de Janeiro/RJ / \\ Brasil. \\ E-mail: eduaraujo00@yahoo.com.br
}

VICTOR RANGEL DOS SANTOS RODRIGUES

Graduando em Ciências Econômicas. Fucape Business School. Endereço: Av. Fernando Ferrari, 1358 / Boa Vista / Vitória/ES / Brasil. E-mail: victorrangelrodrigues@gmail.com

\section{DANILO SOARES MONTE-MOR}

Doutor em Administração e Ciências Contábeis. Fucape Business School. Endereço: Av. Fernando Ferrari, 1358 | Boa Vista / Vitória/ES / Brasil.

E-mail:danilo@fucape.br

\section{ROGÉRIO DIAS CORREIA}

Doutor em Direito. Fucape Business School. Endereço: Av. Fernando Ferrari, 1358 / Boa Vista / Vitória/ES / Brasil.

E-mail: rogeriocorreia@fucape.br

\section{RESUMO}

Este trabalho tem por objetivo identificar quais são os efeitos causados pela divulgação de eventos de corrupção sobre o valor de mercado das empresas listadas na Bolsa de Valores brasileira. Para tanto, utilizou-se a metodologia de estudos de eventos, a fim de avaliar a influência da divulgação das fases de uma das maiores operações anticorrupção brasileira (Operação Lava Jato) sobre o retorno anormal acumulado das ações, tanto de companhias citadas nas investigações (envolvimento direto) quanto de companhias listadas nos setores das companhias citadas. Os resultados indicam que a Lava Jato reduziu o valor de mercado das empresas diretamente envolvidas com os escândalos de corrupção acima de variações que ocorreram no mercado. Já, para as demais empresas dos setores envolvidos, evidenciou-se um efeito positivo sobre o retorno anormal acumulado. Tais resultados sugerem que a deflagração de operações anticorrupção como a Lava Jato tem potencial para reduzir diferenças de precificação existentes entre empresas que participam diretamente de contratos fraudulentos e demais empresas do mesmo setor. Tal ajuste de precificação pode estar associado à correção feita pelo mercado mediante os prejuízos trazidos pela concorrência desleal à competitividade.

Palavras-Chave: Corrupção. Valor de mercado. Operação Lava Jato. 


\begin{abstract}
This paper aims to identify the effects of the disclosure of corruption events on the market values of companies listed on the Brazilian Stock Exchange. For this purpose, we applied the event studies methodology to evaluate the influence of exposing the phases of one of the most extensive Brazilian anti-corruption operations - the Lava Jato Operation - on the cumulative abnormal return of shares, both of the companies cited in the investigations (direct involvement) and of those listed in the same segments as the cited companies. Results indicate that the Lava Jato Operation reduced the market values of the companies directly involved in the corruption scandals above market variations. For the other companies in the concerned segments, there was a positive effect on the cumulative abnormal returns. Such results suggest that the onset of anti-corruption operations such as the Lava Jato Operation has the potential to reduce pricing differences that exist between companies that directly participate in fraudulent contracts and other companies in the same segments. This pricing adjustment may be associated with the correction made by the market due to losses in competiveness caused by unfair competition.
\end{abstract}

Keywords: Corruption. Market value. Lava Jato Operation.

\title{
1 INTRODUÇÃO
}

Noticiários brasileiros frequentemente têm evidenciado eventos de corrupção em várias esferas e hierarquias do poder público, bem como em contratos que envolvem o setor público e a iniciativa privada. Tais notícias seguem alinhadas ao aumento da percepção de corrupção por parte dos brasileiros, à queda do Brasil no ranking do IPC (Índice de Percepção de Corrupção), bem como à deflagração de operações anticorrupção, como é o caso da Operação Lava Jato. Configura-se entre uma das maiores operações anticorrupção brasileiras e possibilitou a descoberta e o desmembramento de diversos esquemas de corrupção por todo o território nacional, os quais contam com a participação de políticos de expressão, grandes empresários e envolvem bilhões de reais (Polícia Federal, 2016).

$\mathrm{Na}$ literatura sobre o tema, autores investigam os efeitos da corrupção sobre o crescimento econômico por meio da análise de fatores como investimentos (Mo, 2001), custos transacionais e eficiência de mercado (Méon \& Weill, 2010), políticas governamentais (Mauro, 1996; 1997), dentre outros. As conclusões ainda são divergentes: alguns resultados sugerem que a corrupção reduz o nível de investimentos e o crescimento econômico devido ao aumento da ineficiência de mercado e da incerteza (Mauro, 1996; Ionescu, 2014); outros estudos sugerem que os efeitos da corrupção podem ser adversos em diferentes economias, a depender de condições e fatores institucionais/socioeconômicos específicos (Blackburn, Bose, \& Haque, 2011; Wang \& You, 2012).

O estudo de Méon e Sekkat (2005), por exemplo, evidencia que o efeito negativo da corrupção nos investimentos e no crescimento econômico é potencializado pela violência política, ineficiência do governo e instituições legais fracas. Méon e Weill (2010), por outro lado, sugerem que os efeitos da corrupção são menos perversos em países com instituições menos desenvolvidas. Além disso, os autores verificam que, em casos de instituições disfuncionais e ineficientes, a corrupção pode até estar relacionada a um aumento relativo de eficiência. Isso porque, nesses casos extremados, os prejuízos causados pela burocracia e morosidade das instituições superam os prejuízos associados à corrupção. Em outras palavras, a corrupção acaba por se apresentar como solução menos custosa, embora ilegal, para o crescimento das empresas (Acemoglu \& Verdier, 1998; Blackburn et al., 2011). Esse é um cenário em que legislações fragilizadas e entraves burocráticos e institucionais acabam por criar incentivos perversos aos agentes da economia.

Não fica claro, entretanto, de que forma a divulgação de eventos de corrupção influencia o valor de mercado de empresas corruptoras e não corruptoras em contextos em que contratos fraudulentos ferem a lealdade da concorrência e interferem nos níveis de competitividade. Este trabalho visa a contribuir para esse debate, ao identificar quais são os efeitos da divulgação de eventos de corrupção sobre o valor de mercado das empresas. 
Especificamente sobre os efeitos da corrupção no mercado financeiro, alguns resultados sugerem que a corrupção reduz o valor da firma via ineficiência de investimentos para as empresas que participam dos contratos fraudulentos (Lee \& $\mathrm{Ng}, 2006$ ). Nesse caso, parte dos recursos investidos é destinada a instituições e funcionários públicos corruptos por meio de pagamentos de propinas (Fisman e Svensson, 2007). O desvio de finalidade de tais recursos aumenta o custo dos produtos e serviços inerentes à atividade empresarial, funcionando como um "imposto" que traz consigo incerteza e risco sobre rentabilidades futuras (Mauro, 1996; Méon \& Sekkat, 2005; Fisman \& Svensson, 2007).

Por outro lado, o estabelecimento de contratos mediante interferências políticas e fraudes em licitações públicas, ao passo em que impõe às demais empresas do mercado uma desvantagem competitiva, proporciona favorecimento e oportunidades às empresas corruptoras, uma vez que produtos e serviços passam a ser adquiridos a despeito do melhor custo-benefício (Lambsdorff, 2003). Nesse caso, a corrupção se configura como um obstáculo à concorrência e confere às empresas corruptoras vantagem competitiva, o que pode gerar pressão por aumento relativo do valor de mercado dessas empresas (Delavallade, 2006). Não fica claro, entretanto, de que forma o mercado precifica e reage à divulgação de eventos de corrupção tanto de empresas diretamente envolvidas em esquemas de corrupção, como de empresas do mesmo setor que indiretamente são envolvidas via desvantagem competitiva.

Para que seja possível compreender quais são os efeitos da divulgação de eventos de corrupção sobre o valor de mercado das empresas, optou-se pelo cenário brasileiro, em meio aos fatos apurados e divulgados pela Operação Lava Jato. Assim, este trabalho tem como objetivo identificar quais são os efeitos causados pela divulgação de eventos de corrupção sobre o valor de mercado das empresas listadas na Bolsa de Valores brasileira.

Em termos teóricos, este trabalho contribui para a literatura ao analisar um cenário específico de corrupção delineada por meio de contratos entre esferas públicas e empresas privadas, somando-se a estudos anteriormente relacionados (Porta, Lopez-de-Silanes, Shleifer, \& Vishny, 1998; Lee \& Ng, 2006), que indicam que a corrupção pode estar relacionada à incerteza de eventos futuros e ao nível de confiança do investidor. Além disso, este estudo se diferencia dos demais trabalhos ao analisar o efeito da divulgação de eventos de corrupção no valor de mercado tanto sobre empresas diretamente envolvidas como em empresas com envolvimento indireto via competitividade de mercado. Em termos práticos, o trabalho indica que o combate à corrupção e a divulgação de fatos apurados pela Operação Lava Jato resultou em perda de valor de mercado para as companhias citadas, e em ganho de valor de mercado para as empresas do mesmo segmento de companhias citadas. Em outras palavras, a divulgação de operações anticorrupção contribui para a redução de discrepâncias de precificação inerentes à corrupção praticada pelas empresas envolvidas nas respectivas operações. Tal ajuste de precificação pode estar associado à correção feita pelo mercado mediante os prejuízos trazidos pela concorrência desleal à competitividade.

\section{REFERENCIAL TEÓRICO}

\subsection{Corrupção e valor de mercado}

Ao analisar os efeitos da corrupção sobre o valor de mercado das firmas, Porta et al. (1998) e Lee e $\mathrm{Ng}$ (2006) sugerem que altos níveis de corrupção no setor público influenciam negativamente o preço das ações das companhias de capital aberto. Controlando por variáveis como ROE ou ROA, margem de lucro, nível de gastos com pesquisa e desenvolvimento, pagamento de dividendos, observou-se que o efeito da corrupção é robusto na depreciação do Price to Book, decorrente das reduções tanto do fluxo de caixa esperado quanto da previsão de lucros futuros. Dessa forma, em determinados níveis a corrupção pode se constituir em um problema para a economia, com o aumento da incerteza e do risco de mercado, resultando na redução de investimentos, com consequências ao desenvolvimento econômico e social (Mauro, 1996; Ehrlich \& Lui, 1999; Lee \& Ng, 2006).

Mauro (1996), por exemplo, destaca que a corrupção gera ineficiência de investimentos, uma vez que parte dos recursos é destinada a instituições e funcionários públicos corruptos por meio de pagamentos de propinas, o que aumenta o custo dos produtos e serviços públicos 
necessários à atividade empresarial, funcionando como um "imposto" que traz consigo a incerteza e o risco sobre acontecimentos futuros (Mauro, 1996; Méon \& Sekkat, 2005; Fisman \& Svensson, 2007).

O'Toole e Tarp (2014) destacam a importância da eficiência dos investimentos, por estar diretamente relacionada ao crescimento econômico e ao produto marginal do capital investido. Em estudo realizado sobre corrupção e eficiência de investimentos em países em desenvolvimento, verificou-se que o efeito da corrupção é negativo. Afeta principalmente as pequenas e médias empresas, uma vez que são, em geral, as mais dependentes dos produtos e serviços públicos, dispondo ainda de menor capacidade de pagamentos.

Alinhados aos estudos anteriores, Everhart, Martinez-Vazquez, Martinez-Varquez e Mcnab (2003) observaram que a corrupção tem a faceta de reduzir a eficiência dos setores público e privado, uma vez que permite que pessoas assumam posições relevantes em diversas esferas de poder, com objetivos diversos ou sem as competências necessárias para promover o fomento. Nesses ambientes instáveis, os retornos sobre os investimentos são mais difíceis de prever, o que afeta as decisões sobre os investimentos privados, com consequência negativa sobre o desenvolvimento econômico e sustentável em longo prazo. Além de reduzir a eficiência do investimento, o estabelecimento de contratos mediante interferências políticas e fraudes em licitações públicas impõe às demais empresas do mercado uma desvantagem competitiva, uma vez que produtos e serviços passam a ser adquiridos a despeito do melhor custo-benefício (Lambsdorff, 2003).

Se por um lado evidencia-se o efeito negativo da corrupção nos investimentos e no crescimento econômico, Méon e Weill (2010), por outro lado, sugerem que os efeitos da corrupção são menos perversos em países com instituições menos desenvolvidas. Além disso, os autores verificam que em casos de instituições disfuncionais e ineficientes, a corrupção pode até estar relacionada a um aumento relativo de eficiência. Isso porque, nesses casos extremados, os prejuízos causados pela burocracia e morosidade das instituições superam os prejuízos associados à corrupção. Em outras palavras, a corrupção acaba por se apresentar como solução menos custosa, embora ilegal, para o crescimento das empresas (Acemoglu \& Verdier, 1998; Blackburn et al., 2011). Esse é um cenário em que entraves burocráticos e institucionais acabam por criar incentivos perversos aos agentes da economia.

O trabalho de Méon e Weill (2010), especificamente, testa duas hipóteses: (1) "Grease on the Wheels", que basicamente defende que a corrupção pode ter efeitos benéficos para a produtividade do país em casos de grave deterioração das instituições, como violência política, Poder Judiciário enfraquecido e administração pública ineficiente; (2) "Sand on the Wheels", hipótese que propõe que a corrupção é perversa em todos os cenários e que seus custos são maiores mesmo nos cenários em que as instituições do país são mais fracas. Resumidamente, as duas hipóteses apontam a corrupção como fator de detrimento econômico em um contexto de instituições fortes e efetivas, porém a hipótese (1) diz que em casos extremos de ineficiência, a corrupção pode ser benéfica, enquanto a hipótese (2) apresenta a corrupção como um entrave ao crescimento independente do cenário.

Os resultados de Méon e Weill (2010) apontam, em média, para uma não rejeição da hipótese "Grease on the Wheels". Ou seja, em países com deterioração do contexto institucional, há indícios da existência de benefícios marginais da corrupção. Os autores ressaltam, entretanto, que tal intepretação é extrema e arriscada, e um país que se beneficiar de tais efeitos pode acabar caindo em uma armadilha futura de pouca eficiência e má gestão.

No equilíbrio, de fato, verifica-se que a economia sempre se encontra em uma situação mais fragilizada quando agentes da economia são submetidos a excesso de burocracia e vivenciam corrupção e instabilidade político-institucional. O fortalecimento das instituições, do ambiente político-econômico e o estabelecimento de punições legais apropriadas a crimes de corrupção, são, portanto, fundamentais para que não sejam criados incentivos perversos aos agentes da economia.

\subsection{A Operação Lava Jato e os custos de agência}

A Operação Lava Jato, de acordo com a Polícia Federal (PF) (Polícia Federal, 2016), é uma investigação de combate a crimes de corrupção e lavagem de dinheiro, que abrange 
diversas empresas de economia mista e privada, acusadas de fraudes em licitações públicas, lavagem de dinheiro e pagamento de propinas. Nesse cenário, os desvios de recursos da Petrobras, principal empresa de economia mista do país, somam bilhões de dólares em fraudes contratuais.

A primeira fase da operação foi deflagrada no dia 17/03/2014 pela PF, com o objetivo de desarticular organizações que praticavam crimes contra Sistema Financeiro Nacional, principalmente a lavagem de dinheiro, oriundos das fraudes contratuais e pagamento de propinas. Os grupos investigados registraram, segundo dados do COAF (Conselho de Controle de Atividades Financeiras/MF), operações financeiras atípicas envolvendo bilhões de reais.

Essas relações contratuais podem ser exploradas pela teoria de Agência. Tal teoria analisa relações comerciais estabelecidas por meio de contratos entre o principal e o agente. São suscetíveis a conflitos e necessitam de mecanismos de governança que limitem os comportamentos dos atores, evidenciando as ações e obrigações das partes, de forma a reduzir o conflito de interesses entre o principal e o agente. Legislações, mecanismos para a redução da assimetria informacional, regras para a alocação de capitais, sistemas de remuneração e recompensa, são utilizados para mitigar riscos e impedir as ações de interesse próprio, com o objetivo de assegurar a eficiência das organizações (Fama \& Jensen, 1983; Brudney, 1985).

Tais mecanismos de governança, entretanto, geram custos de agência, que podem afetar indiretamente o lucro esperado das empresas, devido a altos gastos associados a sistemas burocráticos, ao controle e inibição de comportamentos e ações não desejadas. Não obstante, a omissão desses mecanismos pode significar um aumento de riscos para investidores, com impacto direto no custo de capital da firma. Conforme verificado por Porta et al. (1996), as diferenças e características de sistemas legais e de proteção a investidores são relevantes, tanto para a redução dos custos de agência quanto dos riscos associados a custos de capital. Em regimes mais corruptos, detentores de informações privilegiadas e blocos controladores atuam com maior impunidade, aumentando a incerteza de mercado e a necessidade de mecanismos de proteção. Consequentemente, geram maiores custos de agência.

Exemplos de problemas envolvendo tais mecanismos podem ser dados pelo alvo inicial das investigações da Lava Jato, a Petrobras, na qual agentes públicos por meio do recebimento de propinas facilitavam o fechamento de licitações superfaturadas. Além dessa empresa, outras foram apontadas como participantes dessa rede de corrupção.

Especificamente, as ações da Operação Lava Jato são desmembradas por fases, em parte desdobramentos de fases anteriores. As fases de desdobramentos foram incluídas no estudo por estarem diretamente relacionadas às investigações e cumprimento de mandatos judiciais contra empresas ou pessoas envolvidas nas fraudes, indicando a continuidade e 0 avanço da operação. A Figura 1 representa o resumo das fases e desdobramentos (eventos) das 37 primeiras fases da operação. Informações sobre as demais fases podem ser obtidas junto ao site da PF do Brasil.

\begin{tabular}{|c|c|c|c|c|}
\hline Fase & Data & Objetivo & Resultados & Principais Alvos \\
\hline $1^{\mathrm{a}}$ & $17 / 03 / 2014$ & $\begin{array}{l}\text { Desarticular a ação ilegal de doleiros, que } \\
\text { utilizariam pessoas e empresas em nome de } \\
\text { terceiros, para a prática de crimes contra o } \\
\text { sistema financeiro nacional e lavagem de } \\
\text { dinheiro. }\end{array}$ & $\begin{array}{l}\text { PF cumpre } 81 \text { mandados de } \\
\text { busca e apreensão, } 18 \text { de } \\
\text { prisão preventiva, } 10 \text { de } \\
\text { prisão temporária e } 19 \text { de } \\
\text { condução coercitiva. }\end{array}$ & Doleiros. \\
\hline $2^{a}$ & $20 / 03 / 2014$ & $\begin{array}{l}\text { Apuração da mesma categoria de crimes, com } \\
\text { extensão do foco em outros doleiros e } \\
\text { envolvimento de um ex-diretor da Petrobras. }\end{array}$ & $\begin{array}{l}\text { PF cumpre } 06 \text { mandados de } \\
\text { busca e } 01 \text { de prisão } \\
\text { temporária. }\end{array}$ & $\begin{array}{l}\text { Doleiros, ex-diretor da } \\
\text { Petrobras Paulo } \\
\text { Roberto Costa. }\end{array}$ \\
\hline $3^{\mathrm{a}}$ & $11 / 04 / 2014$ & $\begin{array}{l}\text { Continuação das investigações decorrentes das } \\
\text { fases anteriores. }\end{array}$ & $\begin{array}{l}\text { PF cumpre } 16 \text { mandados de } \\
\text { busca, } 03 \text { de prisão } \\
\text { temporária e } 06 \text { de condução } \\
\text { coercitiva. }\end{array}$ & Doleiros. \\
\hline $4^{\mathrm{a}}$ & $11 / 06 / 2014$ & Desdobramento técnico das fases anteriores. & $\begin{array}{l}\text { PF cumpre } 01 \text { mandado de } \\
\text { busca e } 01 \text { de prisão } \\
\text { preventiva. }\end{array}$ & $\begin{array}{l}\text { Ex-diretor da área de } \\
\text { abastecimento da } \\
\text { Petrobras, Paulo } \\
\text { Roberto Costa. }\end{array}$ \\
\hline
\end{tabular}


Eduardo Carvalho Correa de Araújo, Victor Rangel dos Santos Rodrigues, Danilo Soares Monte-mor, Rogério Dias Correia

\begin{tabular}{|c|c|c|c|c|}
\hline $5^{\mathbf{a}}$ & $01 / 07 / 2014$ & Cumprimento de mandados judiciais. & $\begin{array}{l}\text { PF cumpre } 07 \text { mandados de } \\
\text { busca, } 01 \text { de prisão } \\
\text { temporária e } 01 \text { de condução } \\
\text { coercitiva. }\end{array}$ & $\begin{array}{l}\text { Sócios do doleiro } \\
\text { Alberto Youssef e } \\
\text { empresas de fachada } \\
\text { que movimentavam } \\
\text { contas na Suíça. }\end{array}$ \\
\hline 6 & $22 / 08 / 2014$ & Desdobramento técnico da fase anterior. & $\begin{array}{l}\text { PF cumpre } 15 \text { mandados de } \\
\text { busca e } 01 \text { de condução } \\
\text { coercitiva. }\end{array}$ & $\begin{array}{l}\text { Empresas vinculadas } \\
\text { a Paulo Roberto } \\
\text { Costa. }\end{array}$ \\
\hline $7^{\mathfrak{a}}$ & $14 / 11 / 2014$ & $\begin{array}{l}\text { Prender empreiteiros e operadores do esquema } \\
\text { de distribuição de propinas obtidas mediante } \\
\text { contratos ilícitos com a PETROBRAS. }\end{array}$ & $\begin{array}{l}\text { PF cumpre } 49 \text { mandados de } \\
\text { busca, } 06 \text { de prisão } \\
\text { preventiva, } 21 \text { de prisão } \\
\text { temporária e } 09 \text { de condução } \\
\text { coercitiva. }\end{array}$ & $\begin{array}{l}\text { Presidentes e } \\
\text { executivos de } \\
\text { empreiteiras. }\end{array}$ \\
\hline $8^{\mathbf{a}}$ & $14 / 01 / 2015$ & Desdobramento técnico da fase anterior. & $\begin{array}{l}\text { PF cumpre } 01 \text { mandado de } \\
\text { prisão preventiva. }\end{array}$ & $\begin{array}{l}\text { Ex-diretor da área } \\
\text { internacional da } \\
\text { Petrobras, Nestor } \\
\text { Cerveró. }\end{array}$ \\
\hline $9^{\mathrm{a}}$ & 05/02/2015 & $\begin{array}{l}\text { Apurar o esquema de fraude das licitações da } \\
\text { PETROBRAS e consequente distribuição de } \\
\text { propinas envolvendo demais diretorias da } \\
\text { estatal. }\end{array}$ & $\begin{array}{l}\text { PF cumpre } 40 \text { mandados de } \\
\text { busca e apreensão, } 18 \mathrm{de} \\
\text { condução coercitiva, } 03 \mathrm{de} \\
\text { prisão temporária e } 01 \mathrm{de} \\
\text { prisão preventiva. }\end{array}$ & $\begin{array}{l}\text { Operadores do } \\
\text { esquema de } \\
\text { corrupção. }\end{array}$ \\
\hline $10^{\mathrm{a}}$ & $16 / 03 / 2015$ & $\begin{array}{l}\text { Cumprimento de mandados judiciais para os } \\
\text { crimes de associação criminosa, documento } \\
\text { falso, corrupção passiva e corrupção ativa, } \\
\text { fraude em processo licitatório e lavagem de } \\
\text { dinheiro. }\end{array}$ & $\begin{array}{l}\text { PF cumpre } 02 \text { mandados de } \\
\text { prisão preventiva, } 04 \text { de } \\
\text { prisão temporária e } 12 \text { de } \\
\text { busca e apreensão. }\end{array}$ & $\begin{array}{l}\text { Ex-diretor da área de } \\
\text { serviços da Petrobras } \\
\text { Renato Duque, } \\
\text { operadores e } \\
\text { beneficiários do } \\
\text { esquema. }\end{array}$ \\
\hline $11^{a}$ & $10 / 04 / 2015$ & $\begin{array}{l}\text { Apurar fatos criminosos atribuídos a três grupos } \\
\text { de ex-agentes políticos, no âmbito de desvios de } \\
\text { recursos da Petrobras, e em órgãos públicos } \\
\text { federais. }\end{array}$ & $\begin{array}{l}\text { PF cumpre } 07 \text { mandados de } \\
\text { prisão, } 09 \text { de condução } \\
\text { coercitiva e } 16 \text { de busca e } \\
\text { apreensão. }\end{array}$ & $\begin{array}{l}\text { Políticos e ex- } \\
\text { políticos. }\end{array}$ \\
\hline $12^{\mathrm{a}}$ & $15 / 04 / 2015$ & Cumprimento de mandados judiciais. & $\begin{array}{l}\text { PF cumpre } 01 \text { mandado de } \\
\text { busca e apreensão, } 01 \text { de } \\
\text { prisão preventiva, } 01 \text { de } \\
\text { prisão temporária e } 01 \text { de } \\
\text { condução coercitiva. }\end{array}$ & $\begin{array}{l}\text { Acusados de } \\
\text { recebedor de } \\
\text { vantagens ilícitas } \\
\text { decorrentes de } \\
\text { fraudes em contratos } \\
\text { com a Petrobras. }\end{array}$ \\
\hline $13^{a}$ & $21 / 05 / 2015$ & Desdobramento técnico da fase anterior. & $\begin{array}{l}\text { PF cumpre } 04 \text { mandados de } \\
\text { busca e apreensão, } 01 \text { de } \\
\text { condução coercitiva e } 01 \text { de } \\
\text { prisão preventiva. }\end{array}$ & $\begin{array}{l}\text { Operadores } \\
\text { financeiros que } \\
\text { atuavam junto a } \\
\text { contratos firmados } \\
\text { por empreiteiras com } \\
\text { a Petrobras. }\end{array}$ \\
\hline $14^{\mathrm{a}}$ & $19 / 06 / 2015$ & $\begin{array}{l}\text { Expandir a investigação para os crimes de } \\
\text { formação de cartel, fraude em licitações, } \\
\text { corrupção, desvio de verbas públicas e lavagem } \\
\text { de dinheiro para duas grandes empreiteiras de } \\
\text { atuação nacional e internacional. }\end{array}$ & $\begin{array}{l}\text { PF cumpre } 08 \text { mandados de } \\
\text { prisão preventiva, } 04 \text { de } \\
\text { prisão temporária, } 38 \text { de } \\
\text { busca e } 09 \text { de condução } \\
\text { coercitiva. }\end{array}$ & $\begin{array}{l}\text { Executivos, } \\
\text { empreiteiras e suas } \\
\text { empreiteiras } \\
\text { controladas. }\end{array}$ \\
\hline $15^{\mathrm{a}}$ & $02 / 07 / 2015$ & $\begin{array}{l}\text { Investigar o recebimento de vantagens ilícitas no } \\
\text { âmbito da diretoria internacional da Petrobras. }\end{array}$ & $\begin{array}{l}\text { PF cumpre } 04 \text { mandados de } \\
\text { busca e um de prisão } \\
\text { preventiva. }\end{array}$ & $\begin{array}{l}\text { Ex-diretor da área } \\
\text { internacional da } \\
\text { Petrobras Jorge } \\
\text { Zelada }\end{array}$ \\
\hline $16^{a}$ & $28 / 07 / 2015$ & $\begin{array}{l}\text { Apurar a formação de cartel e o prévio } \\
\text { ajustamento de licitações, além do pagamento } \\
\text { indevido de vantagens financeiras a empregados } \\
\text { da estatal Eletronuclear. }\end{array}$ & $\begin{array}{l}\text { PF cumpre } 23 \text { mandados de } \\
\text { busca, } 02 \text { de prisão } \\
\text { temporária e } 05 \text { de condução } \\
\text { coercitiva. }\end{array}$ & $\begin{array}{l}\text { Presidente da estatal } \\
\text { Eletronuclear. }\end{array}$ \\
\hline $17^{a}$ & $03 / 08 / 2015$ & $\begin{array}{l}\text { Cumprimento de medidas cautelares em relação } \\
\text { a pagadores e recebedores de vantagens } \\
\text { indevidas oriundas de contratos com o Poder } \\
\text { Público. }\end{array}$ & $\begin{array}{l}\text { PF cumpre } 26 \text { mandados de } \\
\text { busca, } 03 \text { de prisão } \\
\text { preventiva, } 05 \text { de prisão } \\
\text { temporária e } 06 \text { de condução } \\
\text { coercitiva. }\end{array}$ & $\begin{array}{l}\text { Políticos, ex-políticos, } \\
\text { lobistas e "laranjas" } \\
\text { utilizados em } \\
\text { transações. }\end{array}$ \\
\hline $18^{\mathrm{a}}$ & $13 / 08 / 2015$ & $\begin{array}{l}\text { Cumprimento de medidas cautelares em relação } \\
\text { ao operador identificado na fase anterior, } \\
\text { responsável por arrecadar valores relacionados } \\
\text { a vantagens ilícitas, obtidas a partir de contrato } \\
\text { no âmbito de crédito consignado junto ao } \\
\text { Ministério do Planejamento. }\end{array}$ & $\begin{array}{l}\text { PF cumpre } 01 \text { mandado de } \\
\text { prisão temporária e } 10 \text { de } \\
\text { busca e apreensão. }\end{array}$ & $\begin{array}{l}\text { Operador identificado } \\
\text { na fase anterior. }\end{array}$ \\
\hline $19 \underline{a}$ & $21 / 09 / 2015$ & $\begin{array}{l}\text { Avanço das investigações das fases anteriores e } \\
\text { de empreiteiras já investigadas na Operação }\end{array}$ & $\begin{array}{l}\text { PF cumpre } 07 \text { mandados de } \\
\text { busca e apreensão, } 01 \text { de }\end{array}$ & $\begin{array}{l}\text { Executivos e } \\
\text { empreiteiras. }\end{array}$ \\
\hline
\end{tabular}




\begin{tabular}{|c|c|c|c|c|}
\hline & & Lava Jato. & $\begin{array}{l}\text { prisão preventiva, } 01 \text { de } \\
\text { prisão temporária e } 02 \text { de } \\
\text { condução coercitiva. }\end{array}$ & \\
\hline $20^{\mathrm{a}}$ & $16 / 11 / 2015$ & $\begin{array}{l}\text { Apurar participação de ex-funcionários da } \\
\text { Petrobras investigados pelo recebimento } \\
\text { indevido de valores por parte de representantes } \\
\text { de empresas contratadas. }\end{array}$ & $\begin{array}{l}\text { PF cumpre } 11 \text { mandados de } \\
\text { busca e apreensão, } 02 \text { de } \\
\text { prisão temporária e } 05 \text { de } \\
\text { condução coercitiva. }\end{array}$ & $\begin{array}{l}\text { Ex-funcionários de } \\
\text { estatal e novo } \\
\text { operador financeiro } \\
\text { identificado. }\end{array}$ \\
\hline $21^{a}$ & $24 / 11 / 2015$ & $\begin{array}{l}\text { Investigar o esquema financeiro utilizado pelos } \\
\text { investigados com o objetivo de ocultar a real } \\
\text { destinação dos valores indevidos pagos a } \\
\text { agentes públicos e diretores da Petrobras. }\end{array}$ & $\begin{array}{l}\text { PF cumpre } 25 \text { mandados de } \\
\text { busca e apreensão, } 01 \text { de } \\
\text { prisão preventiva e } 06 \text { de } \\
\text { condução coercitiva. }\end{array}$ & $\begin{array}{l}\text { Lobista José Carlos } \\
\text { Bumlai, apontado } \\
\text { como amigo do ex- } \\
\text { presidente Luiz Inácio } \\
\text { Lula da Silva. Luiz } \\
\text { Esteves, sócio do } \\
\text { banco de } \\
\text { investimentos BTG } \\
\text { Pactual. }\end{array}$ \\
\hline $22^{\mathrm{a}}$ & $27 / 01 / 2016$ & $\begin{array}{l}\text { Apurar esquema de abertura de empresas } \\
\text { offshore e contas no exterior utilizadas para } \\
\text { ocultar e dissimular recursos oriundos de fraudes } \\
\text { e desvios em contratos com a Petrobras. }\end{array}$ & $\begin{array}{l}\text { PF cumpre } 15 \text { mandados de } \\
\text { busca e apreensão, } 06 \text { de } \\
\text { prisão temporária e } 02 \text { de } \\
\text { condução coercitiva. }\end{array}$ & $\begin{array}{l}\text { Senador Delcídio do } \\
\text { Amaral e banqueiro } \\
\text { André Esteves, sócio } \\
\text { do banco BTG } \\
\text { Pactual. }\end{array}$ \\
\hline $23^{a}$ & 22/02/2016 & $\begin{array}{l}\text { Cumprimento de medidas cautelares } \\
\text { relacionadas ao pagamento e recebimentos de } \\
\text { propinas. }\end{array}$ & $\begin{array}{l}\text { PF cumpre } 38 \text { mandados de } \\
\text { busca e apreensão, } 02 \text { de } \\
\text { prisão preventiva, } 06 \text { de } \\
\text { prisão temporária e } 05 \text { de } \\
\text { condução coercitiva. }\end{array}$ & $\begin{array}{l}\text { Empresas pagadoras } \\
\text { de propina, um } \\
\text { operador e } \\
\text { recebedores de } \\
\text { propina do esquema. }\end{array}$ \\
\hline $24^{a}$ & $04 / 03 / 2016$ & $\begin{array}{l}\text { Apurar o recebimento de vantagens de } \\
\text { empreiteiras diretamente ligadas ao esquema de } \\
\text { corrupção. }\end{array}$ & $\begin{array}{l}\text { PF cumpre } 33 \text { mandados de } \\
\text { busca e apreensão e } 11 \text { de } \\
\text { condução coercitiva. }\end{array}$ & $\begin{array}{l}\text { Ex-presidente Luiz } \\
\text { Inácio Lula da Silva, } \\
\text { seu filho Fábio Luiz } \\
\text { Lula da Silva. }\end{array}$ \\
\hline $25^{a}$ & $21 / 03 / 2016$ & $\begin{array}{l}\text { Cumprimento da prisão do operador apontado } \\
\text { como responsável pelo pagamento de propinas } \\
\text { a ex-diretores da Petrobras. }\end{array}$ & $\begin{array}{l}\text { PF cumpre } 01 \text { mandado de } \\
\text { prisão } 01 \text { de busca e } \\
\text { apreensão, ambos em } \\
\text { Lisboa, Portugal. }\end{array}$ & $\begin{array}{l}\text { Operador Raul } \\
\text { Schmidt Felipe Junior. }\end{array}$ \\
\hline $26^{a}$ & $22 / 03 / 2016$ & $\begin{array}{l}\text { Apurar esquema de contabilidade paralela de um } \\
\text { dos grupos empresariais envolvidos, destinado } \\
\text { ao pagamento de vantagens indevidas a } \\
\text { terceiros, vários deles com vínculos diretos ou } \\
\text { indiretos com o poder público. }\end{array}$ & $\begin{array}{l}\text { PF cumpre } 67 \text { mandados de } \\
\text { busca e apreensão, } 28 \text { de } \\
\text { condução coercitiva, } 11 \text { de } \\
\text { prisão temporária e } 04 \text { de } \\
\text { prisão preventiva. }\end{array}$ & $\begin{array}{l}\text { Grupo empresarial } \\
\text { Odebrecht e } \\
\text { operadores } \\
\text { financeiros ligados ao } \\
\text { mercado paralelo de } \\
\text { câmbio. }\end{array}$ \\
\hline $27^{a}$ & $01 / 04 / 2016$ & $\begin{array}{l}\text { Apurar esquema de lavagem de dinheiro } \\
\text { proveniente de empréstimo junto ao banco } \\
\text { Schahin envolvendo repasse para o Partido dos } \\
\text { Trabalhadores (PT). }\end{array}$ & $\begin{array}{l}\text { PF cumpre } 08 \text { mandados de } \\
\text { busca e apreensão, } 02 \text { de } \\
\text { prisão temporária e } 02 \\
\text { mandados de condução } \\
\text { coercitiva. }\end{array}$ & $\begin{array}{l}\text { Ex-secretário-geral do } \\
\text { PT, Silvio Pereira, ex- } \\
\text { tesoureiro do PT } \\
\text { Delúbio Soares, e } \\
\text { empresários ligados } \\
\text { ao esquema. }\end{array}$ \\
\hline $28^{a}$ & $12 / 04 / 2016$ & $\begin{array}{l}\text { Apurar a cobrança de propinas para evitar a } \\
\text { convocação de empreiteiros para prestarem } \\
\text { depoimento em Comissão Parlamentar de } \\
\text { Inquérito (CPI) instaurada em } 2014 \text { pelo senado } \\
\text { federal e pela câmara de deputados para } \\
\text { investigar desvios na Petrobras. }\end{array}$ & $\begin{array}{l}\text { PF cumpre } 14 \text { mandados de } \\
\text { busca e apreensão, } 01 \text { de } \\
\text { prisão preventiva, } 02 \text { de } \\
\text { prisão temporária e } 05 \text { de } \\
\text { condução coercitiva. }\end{array}$ & $\begin{array}{l}\text { Ex-senador e vice- } \\
\text { presidente da CPI da } \\
\text { Petrobras Gim } \\
\text { Argello. }\end{array}$ \\
\hline $29^{a}$ & $23 / 05 / 2016$ & $\begin{array}{l}\text { Dar prosseguimento às investigações de crimes } \\
\text { de formação de quadrilha, lavagem de dinheiro e } \\
\text { corrupção passiva a ativa, envolvendo verbas } \\
\text { desviadas da Petrobras. }\end{array}$ & $\begin{array}{l}\text { PF cumpre } 06 \text { mandados de } \\
\text { busca e apreensão, } 01 \text { de } \\
\text { prisão preventiva e } 02 \text { de } \\
\text { prisão temporária. }\end{array}$ & $\begin{array}{l}\text { Ex-tesoureiro do } \\
\text { Partido Progressista } \\
\text { João Cláudio Genu e } \\
\text { empresários ligados } \\
\text { ao esquema. }\end{array}$ \\
\hline $30^{\mathrm{a}}$ & $24 / 05 / 2016$ & $\begin{array}{l}\text { Investigar contratos fraudulentos para desvio de } \\
\text { dinheiro da Petrobras. }\end{array}$ & $\begin{array}{l}\text { PF cumpre } 28 \text { mandados de } \\
\text { busca e apreensão, } 02 \text { de } \\
\text { prisão preventiva e } 09 \text { de } \\
\text { condução. }\end{array}$ & $\begin{array}{l}\text { Grupos empresariais, } \\
\text { operadores, e } \\
\text { funcionários da } \\
\text { Petrobras. }\end{array}$ \\
\hline
\end{tabular}




\begin{tabular}{|c|c|c|c|c|}
\hline $31^{\mathrm{a}}$ & 01/07/2016 & $\begin{array}{l}\text { Apurar fraude em processos licitatórios, } \\
\text { pagamentos de propinas a servidores da Caixa } \\
\text { Econômica Federal e da Petrobras, e repasse de } \\
\text { recursos de empresas privadas a partido político } \\
\text { em virtude de sucesso em contratações } \\
\text { específicas. }\end{array}$ & $\begin{array}{l}\text { PF cumpre } 07 \text { mandados de } \\
\text { condução coercitiva, } 04 \text { de } \\
\text { prisão temporária, } 02 \text { de } \\
\text { prisão preventiva e } 42 \text { de } \\
\text { busca e apreensão. }\end{array}$ & $\begin{array}{l}\text { Doleiros a empresas } \\
\text { que mantinham } \\
\text { relações com o ex } \\
\text { presidente da câmara } \\
\text { de deputados } \\
\text { Eduardo Cunha. Ex- } \\
\text { tesoureiro do PT } \\
\text { Paulo Ferreira, e } \\
\text { empresários }\end{array}$ \\
\hline $32^{\mathrm{a}}$ & 07/07/2016 & $\begin{array}{l}\text { Investigar instituição financeira panamenha que } \\
\text { atuava no Brasil clandestinamente e apurar } \\
\text { práticas de crimes contra o Sistema Financeiro } \\
\text { Nacional, lavagem de ativos e organização } \\
\text { criminosa transnacional. }\end{array}$ & $\begin{array}{l}\text { PF cumpre } 07 \text { mandados de } \\
\text { condução coercitiva e } 10 \text { de } \\
\text { busca e apreensão. }\end{array}$ & $\begin{array}{l}\text { Instituição bancária } \\
\text { clandestina FBP } \\
\text { Bank. }\end{array}$ \\
\hline $33^{a}$ & 02/08/2016 & $\begin{array}{l}\text { Apurar a participação da Construtora Queiroz } \\
\text { Galvão no chamado "cartel das empreiteiras", } \\
\text { grupo de empresas com o objetivo de executar } \\
\text { obras contratadas pela Petrobras. }\end{array}$ & $\begin{array}{l}\text { PF cumpre } 23 \text { mandados de } \\
\text { busca e apreensão, } 02 \text { de } \\
\text { prisão preventiva, } 01 \text { de } \\
\text { prisão temporária e } 06 \text { de } \\
\text { condução coercitiva. }\end{array}$ & $\begin{array}{l}\text { Dirigentes e } \\
\text { funcionários da } \\
\text { construtora Queiroz } \\
\text { Galvão. }\end{array}$ \\
\hline $34^{a}$ & $22 / 09 / 2016$ & $\begin{array}{l}\text { Investigar fatos relacionados à contratação pela } \\
\text { Petrobras de empresas para a construção de } \\
\text { duas plataformas. }\end{array}$ & $\begin{array}{l}\text { PF cumpre } 33 \text { mandados de } \\
\text { busca e apreensão, } 09 \text { de } \\
\text { prisão temporária e } 08 \text { de } \\
\text { condução coercitiva. }\end{array}$ & $\begin{array}{l}\text { Empresas Mendes } \\
\text { Junior e OSX, } \\
\text { empresários e } \\
\text { políticos. }\end{array}$ \\
\hline $35^{a}$ & $26 / 09 / 2016$ & $\begin{array}{l}\text { Investigar indícios de uma relação criminosa } \\
\text { entre um ex-ministro da Casa Civil e da Fazenda } \\
\text { com o comando da principal empreiteira do país. }\end{array}$ & $\begin{array}{l}\text { PF cumpre } 27 \text { mandados de } \\
\text { busca e apreensão, } 03 \text { de } \\
\text { prisão temporária e } 15 \\
\text { mandados de condução } \\
\text { coercitiva. }\end{array}$ & $\begin{array}{l}\text { Construtora } \\
\text { Odebrechet, ex- } \\
\text { ministro Antônio } \\
\text { Palocci. }\end{array}$ \\
\hline $36^{a}$ & $10 / 11 / 2016$ & $\begin{array}{l}\text { Investigar lavagem de dinheiro e movimentação } \\
\text { de recursos de origem ilegal, principalmente } \\
\text { oriundos de relações criminosas entre } \\
\text { empreiteiras e empresas sediadas no Brasil com } \\
\text { executivos e funcionários da Petrobras. }\end{array}$ & $\begin{array}{l}\text { PF cumpre } 16 \text { mandados de } \\
\text { busca e apreensão e } 02 \text { de } \\
\text { prisão preventiva. }\end{array}$ & $\begin{array}{l}\text { Operadores } \\
\text { financeiros, } \\
\text { construtoras e outras } \\
\text { empresas contratadas } \\
\text { pela administração } \\
\text { pública. }\end{array}$ \\
\hline $37^{a}$ & $17 / 11 / 2016$ & $\begin{array}{l}\text { Investigar irregularidades e desvio de recursos } \\
\text { de grandes obras contratadas pela } \\
\text { administração pública no estado do Rio de } \\
\text { Janeiro. }\end{array}$ & $\begin{array}{l}\text { PF cumpre } 14 \text { mandados de } \\
\text { busca e apreensão, } 01 \text { de } \\
\text { prisão preventiva e } 02 \text { de } \\
\text { prisão temporária. }\end{array}$ & $\begin{array}{l}\text { Ex-governador Sérgio } \\
\text { Cabral e empreiteiras. }\end{array}$ \\
\hline
\end{tabular}

Figura 1. Fases e Desdobramentos da Operação Lava Jato

Fonte: Adaptado de Polícia Federal, 2016.

\section{METODOLOGIA}

\subsection{Estrutura da pesquisa}

Com o objetivo de identificar quais são os efeitos causados pela divulgação de eventos de corrupção sobre o valor de mercado das empresas listadas na Bolsa de Valores brasileira, utilizou-se pesquisa quantitativa por meio do levantamento de dados secundários obtidos da base Economática e CVM de todos os tipos (classes) de ações das companhias listadas como ativas na B3 durante o período base que compreende de 01/01/2014 a 31/12/2016. Dentro desse período, foram utilizados dados das 37 primeiras fases da operação Lava-Jato, a primeira deflagrada no dia 17/03/2014 e a trigésima sétima em 17/11/2016.

Para capturar o impacto dos eventos de deflagração de cada uma das fases da Operação Lava Jato sobre o retorno das ações das companhias listadas na B3, foi utilizada a metodologia de estudo de evento, que se resume em avaliar como uma informação afeta o mercado em um momento específico, dada a divulgação de um fato presumidamente relevante e não antecipado. Nesse sentido, utilizou-se a soma dos retornos anormais diários de cada empresa nos dias que fazem parte da janela de 01 dia circundante ao evento (CAR_LavaJato), com o objetivo de capturar o conteúdo informacional no entorno desse evento (Kolari \& Pynnone, 2010). 
As análises foram conduzidas considerando-se o efeito das operações tanto nas companhias citadas nas investigações quanto nas demais companhias listadas nos mesmos segmentos das companhias citadas. Nesse último caso, pretende-se, adicionalmente, verificar se operações de corrupção geram transferência informacional entre empresas do mesmo setor. Para que fosse possível controlar pela divulgação de outros eventos que possam influenciar o retorno anormal anual, foram considerados ainda a soma dos retornos anormais diários de cada empresa nos dias que fazem parte da janela de 01 dia circundante a eventos de divulgações obrigatórias e voluntárias feitas pelas respectivas empresas (CAR Obrigatório e CAR Voluntário, respectivamente). O conjunto de informações obrigatório inclui a divulgação do evento referente às demonstrações contábeis, como Balanço Patrimonial, Demonstração do Resultado, Demonstração das Mutações do Patrimônio Líquido, Demonstração do Resultado Abrangente, Demonstração do Valor Adicionado, Notas Explicativas e Relatório de Auditoria, dentre outros. Já os eventos voluntários referem-se a informações dadas ao mercado, como subscrições, dissidências ou recessos, conversões voluntárias, retratações, dentre outras. Tanto as divulgações obrigatórias quanto os comunicados voluntários ao mercado foram coletados manualmente no site da CVM.

Dessa forma, as variáveis independentes CAR_LavaJato, CAR_Obrigatório e CAR_Voluntário representam em termos consolidados, a soma dos CARs dos respectivos tipos de eventos durante o ano, sempre considerando a janela de 01 (um) dia em torno de cada evento de uma mesma espécie (Lava Jato, obrigatório ou voluntário). Nos casos em que um evento de divulgação voluntária caiu na mesma janela de um evento da Lava Jato, considerouse somente o evento da "Lava Jato".O modelo proposto pela equação (1) tem por objetivo verificar se os eventos de divulgação das fases da Java Jato ao longo dos anos de 2014, 2015 e 2016 apresentaram informações que possam explicar os retornos anormais acumulados no ano das ações que compõem o mercado e a reação do mercado para as ações de empresas do mesmo setor das citadas na Lava Jato.

$$
\begin{aligned}
& C A R_{\text {ano }}=\beta_{0}+\beta_{1} \text { CAR Lava Jato }+\beta_{2} \text { CAR Lava Jato * Dummy Citada }+ \\
& +\beta_{3} \text { CAR Lava Jato* Dummy Segmento }+\beta_{4} \text { CAR Obrigatório }+ \\
& +\beta_{5} \text { CAR Voluntário }+ \text { Controles }+ \text { Erro }
\end{aligned}
$$

em que $C A R_{\text {ano }}$ representa o retorno anormal anual acumulado; Dummy Citada assume o valor 1 para as empresas citadas na operação, e 0 caso contrário; Dummy Segmento assume o valor 1 para as empresas que não foram citadas, mas que pertencem ao mesmo setor das empresas citadas, e 0 caso contrário; e CAR Lava Jato, CAR Obrigatório e CARVoluntário representam a soma dos retornos anormais diários de cada empresa nos dias que fazem parte da janela de 01 dia circundante a eventos de operações da Lava Jato, divulgações obrigatórias e divulgações voluntárias, respectivamente.

Tal modelo permite verificar o efeito incremental da divulgação de cada tipo de evento ao retorno anormal acumulado anual. Especificamente, além da possibilidade de verificação do efeito dos retornos anormais no entorno das divulgações das fases da Lava Jato nos retornos anormais acumulados (significância e sentido dos coeficientes $\beta_{1}$ e $\beta_{3}$ ), a análise do $\mathrm{R}^{2}$ ajustado em especificações que considerem e não considerem a variável CAR Lava Jato tem potencial para indicar a relevância incremental que as informações que nortearam as fases da Lava Jato têm para explicar variações anormais dos retornos das ações ao longo do ano. A escolha do modelo descrito em (1) segue alinhada à metodologia utilizada por Basu, Mcgavock e Zhang (2013).

Em linhas gerais, os resultados obtidos apontam para um efeito negativo sobre o retorno anormal acumulado no ano de ações de empresas citadas nas fases da Lava Jato, e um efeito positivo sobre o retorno anormal acumulado de ações de empresas de mesmo segmento das empresas citadas. Não obstante, verificou-se que o efeito sobre o retorno anormal anual acumulado das ações de companhias que não foram citadas na Lava Jato e que não estão listadas no mesmo segmento das empresas citadas é estatisticamente igual à zero. 
Esses achados sugerem que os eventos da Operação Lava Jato, embora não tenham influenciado de forma significativa as empresas que não foram citadas e que não estão listadas no mesmo segmento de atuação de empresas citadas, tiveram efeito nos retornos de empresas afetadas direta e indiretamente pela operação. Isso se torna relevante na análise de abrangência dos impactos da Operação Lava Jato sobre o mercado de ações no Brasil.

Especificamente, os resultados indicam que a operação reduziu o valor de mercado das empresas diretamente envolvidas com os escândalos de corrupção acima de variações que ocorreram no mercado. Tal evidência segue alinhada à Everhart, Martinez e McNab (2003), cujos achados sugerem que, na presença de corrupção, os retornos sobre os investimentos são mais difíceis de prever, o que afeta as decisões sobre os investimentos privados, com consequência negativa sobre o desenvolvimento econômico e sustentável no longo prazo.

A Figura 2 apresenta as empresas citadas nas investigações no período que abrange da primeira à trigésima sétima fases. Desse quadro, tem-se o conjunto de empresas "citadas" na operação "Lava Jato" e as respectivas fases em que houve a citação. Com base nesses dados, diferenciam-se as empresas citadas das não citadas na Operação Lava Jato.

\begin{tabular}{|c|c|c|c|}
\hline EMPRESA & SEGMENTO BOVESPA & $\begin{array}{l}\text { SEGMENTO } \\
\text { DE } \\
\text { LISTAGEM } \\
\end{array}$ & $\begin{array}{l}\text { CITAÇÃO } \\
\text { LAVA JATO }\end{array}$ \\
\hline BRASKEM & Materiais Básicos / Químicos / Petroquímicos & $\mathrm{N} 1$ & $14^{\mathrm{a}} ; 35^{\mathrm{a}}$ fase \\
\hline JBS & $\begin{array}{|lll|}\text { Consumo não Cíclico / Alimentos } \\
\text { Processados / Carnes e Derivados }\end{array}$ & NM & $31^{\mathrm{a}}$ fase \\
\hline ELETROBRAS & $\begin{array}{l}\text { Utilidade Pública / Energia Elétrica / Energia } \\
\text { Elétrica }\end{array}$ & N1 & $16^{\underline{a}}$ fase \\
\hline GOL & $\begin{array}{l}\text { Bens Industriais / Transporte / Transporte } \\
\text { Aéreo }\end{array}$ & N2 & $31^{\text {a }}$ fase \\
\hline HYPERMARCAS & $\begin{array}{l}\text { Consumo não Cíclico / Diversos / Produtos } \\
\text { Diversos }\end{array}$ & NM & $31^{\mathrm{a}}$ fase \\
\hline PETROBRAS & $\begin{array}{l}\text { Petróleo. Gás e Biocombustíveis / Petróleo. } \\
\text { Gás e Biocombustíveis / Exploração. Refino } \\
\text { e Distribuição }\end{array}$ & - & 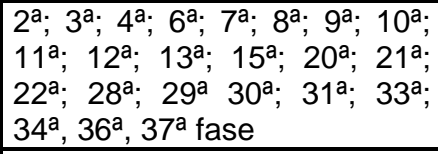 \\
\hline Ol & \begin{tabular}{|l|l|} 
Telecomunicações / Telecomunicações // \\
Telecomunicações
\end{tabular} & N1 & $23^{a}$ fase \\
\hline BTG Pactual & $\begin{array}{l}\text { Financeiro e Outros / Serviços Financeiros } \\
\text { Diversos / Gestão de Recursos e } \\
\text { Investimentos }\end{array}$ & DDR3 & $21^{\text {a }}$ fase \\
\hline BTG Banco & $\begin{array}{|llll|}\text { Financeiro e Outros / Intermediários } \\
\text { Financeiros / Bancos }\end{array}$ & - & $21^{a}$ fase \\
\hline
\end{tabular}

Figura 2. Amostra de Empresas Citadas na "Lava Jato" que possuem ações negociadas na BM\&F Bovespa

Fonte: Adaptado de Polícia Federal, 2016; Bovespa, 2016.

\subsection{Tratamento dos dados}

Com base no modelo proposto, as observações para o cálculo do CAR foram consolidadas em ações de diferentes classes e empresas no ano. A base foi inicialmente composta por 371 companhias somando 579 classes de ações, em um total de 453.412 observações diárias, no período base. Para o tratamento dos dados, foram eliminadas as empresas que não apresentavam qualquer retorno diário no período de 365 dias. Ao todo, foram excluídas 152.447 observações, restando 300.965 observações referentes a 298 empresas e 411 ações.

Foram excluídas, também, na seguinte ordem: 33.488 observações de companhias com Patrimônio Líquido negativo; 32.886 observações de companhias listadas no segmento "Finanças e Seguros" no Economática; 73 observações de empresas que não possuíam dados consolidados dos controles ROA, Alavancagem Financeira, Ativo Total, Valor de Mercado, durante o período analisado. Após o tratamento e consolidação dos dados diários de retorno em dados anuais, restaram 243 empresas e 329 classes, somando 866 observações de 
empresas-classe-ano no período base. As variáveis de controle foram winsorizadas a $2,5 \%$ como forma de mitigar a possível influência de outliers nos resultados.

\subsection{Cálculo dos retornos anormais acumulados}

Para o cálculo dos retornos anormais acumulados, foi utilizado o modelo estatístico ajustado ao mercado, amplamente utilizado para o cálculo de retornos anormais em estudos de evento (Brown \& Warner, 1980), conforme equação (2):

$$
\text { ARit }=\text { Rit }- \text { Rmt }
$$

em que:

ARit = retorno anormal da ação $i$ na data $t$

Rit $=$ retorno da ação $i$ na data $t$

$\mathrm{Rmt}=$ retorno médio de mercado na data $t$

Em um primeiro momento, foi calculado o retorno da ação $i$ na data $t$ (Rit) de todas as empresas listadas na BM\&F Bovespa, em todos os dias do período base, pelo método logaritmo:

$$
\text { Rit }=\operatorname{Ln}\left(\frac{p_{t}}{p_{t-1}}\right)
$$

Posteriormente, foi calculado o retorno médio de mercado na data $t$ (RMt) pelo método Market Value-Weight Return, resultado do somatório do retorno do portfólio de mercado ponderado pelo seu respectivo peso $(\mathrm{Wi})$ em reais $(\mathrm{R} \$)$ sobre o valor total do mercado na data $t$ em reais $(\mathrm{R} \$)$. Foram desconsideradas para o cálculo as ações de empresas citadas na Operação Lava Jato.

$$
\mathrm{RMt}=\sum_{t=1}^{T} \text { Rit.Wit }
$$

Para padronizar os retornos anormais dos diferentes ativos, divide-se o retorno em excesso da ação por seu desvio padrão, gerando assim um coeficiente de retorno anormal (SAR), conforme apresentado na equação (5) (McWilliams \& Siegel, 1997):

$$
\text { Standardized Abnormal Return: SAR }=\frac{A R_{\text {it }}}{\sigma_{\text {it }}}
$$

em que:

$\sigma_{\bar{i}}=$ desvio padrão da ação $i$ na data do evento, calculado sobre os 365 dias anteriores.

Por fim, calcula-se o retorno anormal acumulado da ação durante a janela do evento, pelo somatório dos retornos anormais padronizados:

$$
C A R_{i t}=\sum_{t=1}^{T} \text { SARit }
$$

\subsection{Variáveis de controle}

Como variáveis de controle, optou-se por indicadores com base em informações contábeis, relevantes para os acionistas, investidores, e para o mercado (Kulmar \& Sopariwala, 1992; Hitt, Hoskisson, Johnson e Moesel, 1996; Gompers, Ishii, \& Metrick, 2003). São eles:

- Rentabilidade: Lee e $\mathrm{Ng}$ (2006) verificaram que o impacto da corrupção sobre o valor para os acionistas é robusto, controlado por indicadores estatisticamente significativos, como a rentabilidade histórica (ROE ou ROA);

- Tamanho: Fama e French (1992) verificaram que os retornos médios de empresas com baixo valor de mercado seriam maiores do que o previsto em função dos seus betas estimados;

- Liquidez: Para Amihud e Mendelson (1988), os investidores estão dispostos a pagar mais por ativos de maior liquidez, ao passo que esperam um maior retorno para ativos de menor liquidez;

- Endividamento: o grau de alavancagem financeira seria uma condição de fator de risco adicional ao beta das ações, positivamente relacionado com os retornos anormais (Bhandari, 1988);

- Book-to-Market: o valor contábil e o valor de mercado estão relacionados com oportunidades de crescimento, custos financeiros e lucratividade da firma (Chen \& Zhao, 2006). 


\begin{tabular}{|l|l|l|}
\hline Variável & Análise & Fórmula \\
\hline Retorno sobre o Ativo (ROA) & Rentabilidade & $\frac{\text { Lucro Líquido }}{\text { Total do Ativo }}$ \\
\hline Negociações em Bolsa & Liquidez & Volume Negociado \\
\hline Total do Ativo & Tamanho Ativo Total \\
\hline Grau de Alavancagem Financeira & Endividamento & $\frac{\text { LucroLiquído } / \text { Lucro Liquido }}{\text { Totaldo Ativo }}$ \\
\hline Book to Marketing & Oportunidade de Crescimento & PL / Valor de Mercado \\
\hline
\end{tabular}

Figura 3. Quadro Resumo - Variáveis de Controle Utilizadas no Modelo

Fonte: Elaboração própria.

\section{RESULTADOS}

\subsection{Estatística descritiva}

Com base na análise da Tabela 1, observa-se que tanto o CAR de eventos voluntários quanto o CAR de eventos da Lava Jato possuem desvio padrão aproximadamente três vezes maior do que o CAR de eventos obrigatórios. Sugere que os eventos não obrigatórios, tais como comunicados voluntários e eventos relacionados à Operação Lava Jato possam estar associados a uma maior volatilidade dos ativos listados em bolsa.

Tabela 1

\section{Estatística Descritiva das Variáveis}

A estatística descritiva das variáveis utilizadas no modelo apresentam as medidas de posição e dispersão, com informações relativas ao conjunto de ações de companhias listadas na BM\&F Bovespa ativas no período base dentro dos parâmetros adotados neste trabalho.

\begin{tabular}{lccccc}
\hline Variável & Média & Mediana & $\begin{array}{c}\text { Desvio } \\
\text { Padrão }\end{array}$ & 10 Quartil & 3⿻ Quartil \\
\hline CAR_Ano & 0.07 & -0.01 & 1.10 & -0.21 & 0.13 \\
CAR_LavaJato & -0.00 & 0.00 & 0.31 & -0.05 & 0.02 \\
CAR_Obrigatório & -0.01 & 0.00 & 0.10 & -0.01 & 0.01 \\
CAR_Voluntário & 0.02 & 0.00 & 0.34 & -0.02 & 0.03 \\
ROA & 1.72 & 2.50 & 7.77 & -1.10 & 5.90 \\
Alavancagem Financeira & 3.04 & 1.61 & 8.85 & 0.95 & 2.67 \\
Liquidez & 0.21 & 0.01 & 0.45 & 0.00 & 0.17 \\
Ln(Ativo_Total) & 15.10 & 15.24 & 1.73 & 13.89 & 16.25 \\
Book-to-Market & 1.59 & 1.05 & 1.55 & 0.54 & 2.09 \\
\hline
\end{tabular}

Fonte: Elaboração própria.

Destaca-se que tanto o CAR_LavaJato quanto o CAR_Obrigatório apresentam valores médios negativos, enquanto o CAR_Voluntário apresenta, em média, valores positivos. Tais resultados apresentam evidências de que investidores penalizaram o mercado brasileiro no período de divulgação das informações da Lava Jato, e que a divulgação dos balanços contábeis das empresas esteve cercada de surpresas negativas com resultados inferiores às expectativas do mercado.

Tais análises, entretanto, não permitem verificar se a diminuição de valor das empresas durante a divulgação das fases da Lava Jato referem-se a movimentações sistêmicas ou se empresas foram afetadas de forma diferente pelas operações. Na próxima seção apresenta-se o efeito da operação para empresas direta e indiretamente envolvidas, comparadas com empresas de seguimentos que não possuem envolvimento com aquela operação.

\subsection{Resultados da regressão}

A Tabela 2 apresenta quatro diferentes especificações para o modelo 1, que considera o efeito da divulgação de eventos obrigatórios (CAR_Obrigatório), voluntários (CAR_Voluntário) e da Lava Jato (CAR_LavaJato) no retorno anormal acumulado anual (CAR_Ano) das empresas brasileiras. A coluna $A$ da Tabela 3 apresenta uma especificação que considera apenas a influência de eventos obrigatórios. A coluna B passa a levar também em consideração o efeito de eventos voluntários.

Já as especificações das colunas C e D consideram igualmente a influência da Lava Jato. Especificamente, a coluna $C$ permite verificar se a Lava Jato teve influência no mercado 
brasileiro, independentemente das empresas terem sido citadas ou não. Já a especificação $D$ segrega o efeito da Lava Jato entre as empresas citadas e aquelas que pertencem ao mesmo setor das citadas em relação às demais empresas que não têm qualquer relação.

Os resultados das estimações da especificação A mostram que o coeficiente da variável CAR_Obrigatório é significativo a $95 \%$ de confiança. Tais evidências sugerem que as divulgações obrigatórias trazem informações relevantes que são precificadas pelo mercado também no caso brasileiro. $O R^{2}$ do modelo constante na especificação $A$, entretanto, foi de apenas $1,28 \%$, o que sugere que outros eventos possam ter relevância informacional para explicar variações no retorno anormal acumulado anual da empresa. Tal resultado corrobora evidências apresentadas em Ball e Shivakumar (2008), cujos resultados apontam para uma presença discreta de novas informações durante a divulgação dos balanços trimestrais.

Considerando-se, na especificação $B$, os eventos de divulgação voluntária, observa-se um coeficiente significativo para o CAR_Voluntário a $99 \%$ de confiança, bem como um aumento do $R^{2}$ para $5,86 \%$. Tal resultado possui duas interpretações: i) tal como em Ball e Shivakumar (2008), a significância do coeficiente e o aumento do poder explicativo do modelo indicam que os eventos voluntários trazem novas informações para o mercado brasileiro, que permitem explicar melhor as variações dos retornos anormais acumulados anualmente; ii) entretanto, embora o $\mathrm{R}^{2}$ tenha aumentado, o valor de 5,86\% segue alinhado ao de Basu et al. (2013), quando é considerada a amostra completa tanto de empresas que fizeram quanto de empresas que não fizeram divulgações voluntárias anualmente. Nesse caso, percebe-se que o poder explicativo, embora maior, ainda sugere a existência de outras informações que consideravelmente têm potencial para explicar variações do retorno anormal anual das empresas.

As especificações constantes nos Painéis C e D apresentam evidências de que, no caso brasileiro, a Lava Jato é uma dessas fontes de grande relevância informacional. Note-se que o coeficiente da variável CAR_LavaJato foi significativo a $99 \%$ de confiança na especificação $C$, o que sugere que a Lava Jato influenciou o retorno das ações do mercado. Além disso, o $\mathrm{R}^{2}$ obtido de $25,67 \%$, valor consideravelmente maior que o da regressão anterior $(5,86 \%)$, indica que a Lava Jato impactou de forma relevante o mercado brasileiro.

Segregando-se tal efeito entre empresas citadas e empresas do mesmo segmento em relação àquelas sem vínculo com a operação, conforme especificação $D$, percebe-se que 0 conteúdo informacional da Lava Jato é significativo apenas para as empresas envolvidas na operação de forma direta e para as empresas não envolvidas diretamente, mas pertencentes aos setores afetados pela operação. Observa-se, nesse caso, que o coeficiente das empresas sem envolvimento (0.3009) não foi significativo, e que o coeficiente das empresas citadas (3.6922) e das que pertencem ao mesmo setor (1.3408) foram significativos a $95 \%$ e $99 \%$ de confiança, respectivamente.

O coeficiente negativo referente à interação CAR_LavaJato*DummyCitadas evidencia o custo gerado pela operação Lava Jato às empresas diretamente envolvidas nos escândalos de corrupção. Tais resultados indicam que a operação reduziu o valor de mercado dessas empresas acima de variações que ocorreram no mercado, o que segue alinhado a Macnab (2003), cujos resultados sugerem que, na presença de corrupção, os retornos sobre os investimentos são mais difíceis de prever. O resultado afetou as decisões sobre os investimentos privados, com consequência negativa sobre o desenvolvimento econômico e sustentável em longo prazo.

Analisando-se as empresas indiretamente envolvidas por meio da interação CAR_LavaJato*DummySegmento, verifica-se um resultado oposto das empresas citadas diretamente. Especificamente, as informações contidas na Lava Jato influenciaram de forma positiva o retorno anormal das empresas não envolvidas, mas pertencentes ao segmento de empresas com envolvimento direto. Tal resultado corrobora evidências da literatura de que a corrupção tende a ser um obstáculo à concorrência, uma vez que o estabelecimento de contratos mediante interferências políticas e fraudes em licitações públicas impõe às demais empresas do mercado uma desvantagem competitiva, dado que produtos e serviços passam a ser adquiridos das empresas corruptoras a despeito do melhor custo-benefício (Lambsdorff, 2003). Nesse caso, a divulgação de operações anticorrupção contribui para a redução de discrepâncias de precificação inerentes à corrupção praticada pelas empresas envolvidas nas 
respectivas operações. Tal ajuste de precificação pode estar associado à correção feita pelo mercado mediante os prejuízos trazidos pela concorrência desleal à competitividade.

Tabela 2

Efeito da Operação Lava Jato no Retorno de Empresas com e sem Envolvimento

\begin{tabular}{|c|c|c|c|c|c|c|c|c|}
\hline \multicolumn{9}{|c|}{ 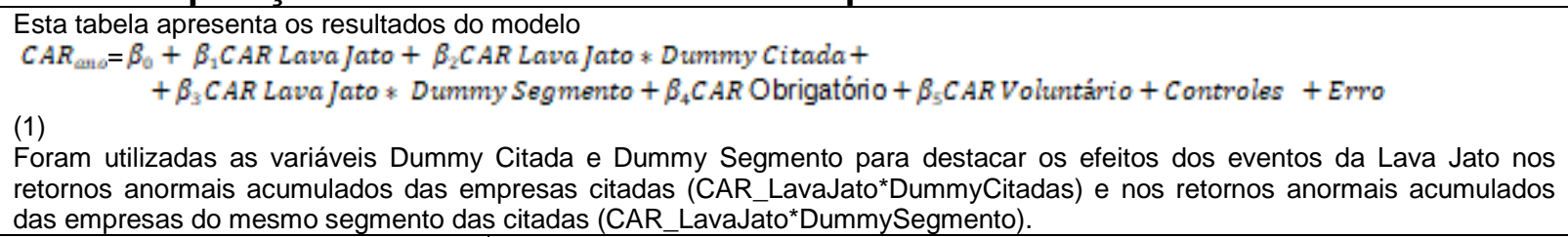 } \\
\hline \multirow[t]{3}{*}{ иал } & \multicolumn{8}{|c|}{ Especificações } \\
\hline & \multicolumn{2}{|c|}{ A } & \multicolumn{2}{|c|}{ B } & \multicolumn{2}{|c|}{ C } & \multicolumn{2}{|c|}{ D } \\
\hline & & & & & & & Coef. & \\
\hline CAR_Obrigatório & .9527 & 0.027 & 1.3183 & 0.00 & & & 1.5 & \\
\hline CAR_Voluntário & & & .8385 & 0.000 & 1. & 0.000 & 1.1861 & 0.000 \\
\hline CAR_LavaJato & & & & & 1.1472 & 0.000 & & \\
\hline CAR_LavaJato*Dumm & & & & & & & & \\
\hline CAR_LavaJato*DummySegmento & & & & & & & 1.3408 & 0.000 \\
\hline & -.0046 & 0.554 & 00 & 0.5 & & & & \\
\hline gem Financ & & & & & & & & \\
\hline Liquide & .2994 & 0.427 & .0694 & 0.847 & -.1446 & 0.666 & .0126 & 0.969 \\
\hline Total) & & .3 & & 0.43 & & & & \\
\hline ook-to-Market & & & & & & & & 0.0 \\
\hline R-sq: overall & \multicolumn{2}{|c|}{0.0128} & \multicolumn{2}{|c|}{0.0586} & \multicolumn{2}{|c|}{0.2567} & \multicolumn{2}{|c|}{0.2565} \\
\hline
\end{tabular}

Fonte: Elaboração própria.

Em relação aos controles, observa-se que, em todas as regressões, a variável Book to Market (BtM) apresenta coeficiente estatisticamente positivo. Indica relevância explicativa sobre a variável dependente, a um nível de $90 \%$ de confiança, o que corrobora o modelo proposto por Ohlson (1995), que relaciona o BtM aos retornos anormais acumulados, e por Chen e Zhao (2006), que relaciona o indicador à possibilidade de crescimento e lucratividade da firma, consequentemente ao seu valor de mercado. Na regressão $A$, a variável de controle Alavancagem Financeira também apresentou coeficiente positivo estatisticamente significativo a $90 \%$ de confiança para explicar os retornos anormais acumulados, provendo indícios de sua capacidade explicativa sobre retornos anormais. As demais variáveis de controle não apresentaram resultados estatisticamente significativos em qualquer das regressões. Sugere que não possuem influência sobre a variável dependente do modelo.

\subsection{Análise de sensibilidade}

No geral, os resultados do modelo proposto indicam que os eventos da Operação Lava Jato, embora não tenham influenciado de forma significativa as empresas que não estão listadas no mesmo segmento de atuação de empresas citadas, tiveram efeito nos retornos de empresas afetadas direta e indiretamente pela operação. Não fica claro, entretanto, se os efeitos obtidos referem-se a diferenças pré-existentes entre os grupos analisados ou se de fato são efeitos associados aos desdobramentos da operação.

Com o objetivo de verificar se empresas citadas já apresentavam diferenças de retornos em relação a empresas com nenhuma relação com a Lava Jato, mesmo antes do início das operações, realizou-se testes t de diferença de médias que comparam as médias das variáveis de controle e variáveis CAR levando-se em consideração dados de 2013 de empresas citadas na Lava Jato (Citadas) com o grupo de empresas que não foram citadas e não pertencem ao setor das citadas (Nenhuma Relação).

Comparando-se as empresas citadas com as empresas sem relação com a Lava Jato em termos de retornos anormais acumulados, verifica-se, conforme painel B da tabela 2, que não há diferenças estatisticamente significativas entre as médias de retorno anormal tanto no âmbito do conjunto total de informações anual (CAR_Ano) quanto para informações obrigatórias (CAR_Obrigatório) e voluntárias (CAR_Voluntário). Tais resultados são importantes na medida em que indicam que, em termos de retorno e conteúdo informacional, os grupos de empresas analisados não eram diferentes no período anterior à Lava Jato.

Além disso, conforme apontado pelo painel $\mathrm{A}$ da tabela 3 , com relação às variáveis de controle Liquidez em Bolsa e Ativo Total, o teste de diferença das médias apresentou 
coeficiente significativo a um nível de $99 \%$ de confiança, o que indica a existência de diferenças estatisticamente significativas para esses dois indicadores entre as empresas Citadas e Não Citadas na Operação Lava Jato. Dessa forma, verifica-se que em média a Liquidez em Bolsa e Ativo Total das empresas citadas eram superiores aos das empresas não citadas na Operação Lava Jato.

Tais resultados indicam que, no geral, as empresas citadas na "Lava Jato" são aquelas que em média já possuíam maior liquidez e maior tamanho (ativo total) no período anterior ao início da operação. Como o modelo utilizado em (1) busca capturar a relevância informacional que janelas em torno das fases Lava-Jato possuem para explicar o retorno anormal anual, verifica-se uma menor sensibilidade dos coeficientes do modelo utilizado (referentes a janelas de 3 dias) em relação a variações de tamanho e liquidez das empresas (variações anuais). Entretanto, tal resultado ressalta a importância de se controlar por tamanho e liquidez em modelos de valuation que envolvam corrupção em empresas brasileiras. Para as variáveis ROA, Alavancagem Financeira e Book to Market, não foram observadas diferenças estatisticamente significativas entre os grupos de empresas citadas e não citadas em período anterior ao início da operação "Java Jato".

\section{Tabela 3}

\section{Teste de Diferença de Médias entre as empresas Citadas e empresas com Nenhuma Relação com a Lava Jato}

O painel apresenta os testes de diferença de médias entre as empresas sem relação com a "Lava Jato" e as empresas citadas na operação. Buscou-se avaliar se existem diferenças iniciais significativas entre estes dois grupos, independente dos eventos da Operação Lava Jato. Para tanto, comparou-se as ações de empresas utilizando os dados do consolidado de 2013, período imediatamente anterior ao período de início da Operação Lava Jato, considerando-se tanto as variáveis de controle (Painel $A$ ), quanto informações referentes às divulgações obrigatórias e voluntárias (Painel B).

Painel A: Comparação das empresas citadas e sem relação com a Lava Jato com relação às variáveis de controle no ano de 2013.

\begin{tabular}{lcc|cc|cc}
\hline & \multicolumn{2}{c}{ Nenhuma Relação } & \multicolumn{2}{c|}{ Citadas } & \multicolumn{2}{c}{ Dif. de Médias } \\
\hline Variável & Média & Desvio Padrão & Média & Desvio Padrão & A-B & P-Valor \\
\hline ROA & 1.245 & 17.467 & -0.2 & 3.834 & -0.755 & 0.827 \\
\hline Alavancagem Fin. & 2.535 & 4.613 & 1.117 & 1.528 & 1.007 & 0.418 \\
\hline Liquidez & 0.192 & 0.334 & 0.622 & 0.486 & -0.43 & 0.0012 \\
\hline Ln(Ativo Total) & 14.851 & 1.530 & 17.688 & 1.048 & $-2,837$ & 0.000 \\
\hline Book_to_Mkt & 0.866 & 0.823 & 1.362 & 1.207 & $-0,496$ & 0.125 \\
\hline
\end{tabular}

Painel B: Comparação das empresas citadas e sem relação com a Lava Jato com relação CARs no ano e em torno das janelas de eventos obrigatórios e voluntários em 2013.

\begin{tabular}{lcc|cc|cc}
\hline & \multicolumn{2}{c}{ Nenhuma Relação } & \multicolumn{2}{c}{ Citadas } & \multicolumn{2}{c}{ Dif. de Médias } \\
\hline CAR_Ano & 0.0363 & 1.052 & -0.0154 & 0.2442 & 0.0517 & 0.785 \\
\hline CAR_Obrigatório & -0.0133 & 0.1293 & -0.0110 & 0.0543 & -0.0022 & 0.923 \\
\hline CAR_Voluntário & 0.0123 & 0.3099 & -0.0630 & 0.3607 & 0.0754 & 0.200 \\
\hline
\end{tabular}

Fonte: Elaboração própria.

\section{CONCLUSÃO}

O presente estudo teve como objetivo identificar quais são os efeitos causados pela divulgação de eventos de corrupção sobre o valor de mercado das empresas listadas na Bolsa de Valores brasileira. Os resultados da pesquisa apontam que os eventos relacionados à corrupção, divulgados pela Operação Lava Jato, possuem maior relevância informacional para explicar variações do retorno anormal acumulado anual das companhias listadas na bolsa brasileira do que eventos de divulgação obrigatória (eventos de natureza contábil e financeira) e eventos de divulgação voluntária.

Adicionalmente, os resultados apontam para um efeito negativo sobre o retorno anormal acumulado no ano de ações de empresas citadas nas fases da Lava Jato, e um efeito positivo sobre o retorno anormal acumulado de ações de empresas de mesmo segmento das empresas citadas. Não obstante, verificou-se que o efeito sobre o retorno anormal anual acumulado das ações de companhias que não foram citadas na Lava Jato e que não estão listadas no mesmo segmento das empresas citadas é estatisticamente igual a zero. Esses achados sugerem que 
os eventos da Operação Lava Jato, embora não tenham influenciado de forma significativa as empresas que não foram citadas e que não estão listadas no mesmo segmento de atuação das citadas, tiveram efeito nos retornos de empresas afetadas direta e indiretamente pela operação.

Especificamente, os resultados indicam que a operação reduziu o valor de mercado das empresas diretamente envolvidas com os escândalos de corrupção acima de variações que ocorreram no mercado. Tal evidência segue alinhada a Macnab (2003), cujos achados sugerem que, na presença de corrupção, os retornos sobre os investimentos são mais difíceis de prever, o que afeta as decisões sobre os investimentos privados, com consequência negativa sobre o desenvolvimento econômico e sustentável no longo prazo.

Analisando-se as empresas indiretamente envolvidas, verifica-se um resultado oposto das empresas citadas diretamente. Especificamente, as informações contidas na Lava Jato influenciaram de forma positiva o retorno anormal das empresas não envolvidas, mas pertencentes ao mesmo segmento. Tal resultado corrobora evidências da literatura de que a corrupção tende a ser um obstáculo à concorrência, uma vez que proporciona favorecimento e oportunidades às empresas corruptoras, como o estabelecimento de contratos mediante fraude em licitações públicas, em que produtos e serviços são adquiridos a despeito do melhor custobenefício (Lambsdorff, 2003),

Esses achados sugerem que os eventos da Operação Lava Jato, embora não tenham influenciado de forma significativa as empresas que não foram citadas e que não estão listadas no mesmo segmento de atuação de empresas citadas, tiveram efeito nos retornos de empresas afetadas direta e indiretamente pela operação. Isso se torna relevante na análise de abrangência dos impactos da Operação Lava Jato sobre o mercado de ações no Brasil.

No geral, os resultados em parte sustentam a hipótese "Grease on the Wheels" de Méon e Weill (2010) e acendem um alerta para o cenário brasileiro. Os resultados de Méon e Weill (2010) indicam que, em média, em países com deterioração do contexto institucional, há indícios da existência de benefícios marginais da corrupção. A redução do valor de mercado de empresas diretamente citadas e o aumento do valor de mercado das empresas envolvidas indiretamente pode estar refletindo um desequilíbrio competitivo do mercado, no qual empresas que se envolvem em esquemas de corrupção passam a ter vantagem competitiva em relação às demais empresas do mesmo segmento.

No equilíbrio, entretanto, verifica-se que a economia sempre se encontra em uma situação mais fragilizada na presença da corrupção. O fortalecimento das instituições, do ambiente político-econômico e o estabelecimento de punições legais apropriadas a crimes de corrupção, são, portanto, fundamentais para que não sejam criados incentivos perversos aos agentes da economia.

Como contribuição, este trabalho evidencia empiricamente os efeitos da divulgação da corrupção sobre o mercado de ações brasileiro a partir de contratos fraudulentos estabelecidos entre esferas do setor público e a iniciativa privada. Os resultados são ainda mais relevantes por analisar um cenário específico em que se tem uma grande investigação contra crimes de corrupção em curso (Operação Lava Jato), que proporciona uma gama de informações e dados de corrupção verificada por meio de fatos que se tornam públicos. Além disso, este estudo se diferencia dos demais trabalhos ao analisar o efeito da divulgação de eventos de corrupção no valor de mercado tanto sobre empresas diretamente envolvidas como pobres empresas com envolvimento indireto via competitividade de mercado.

Em termos práticos, o trabalho indica que o combate à corrupção e a divulgação de fatos apurados pela Operação Lava Jato resultou em perda de valor de mercado para as companhias citadas, e em ganho de valor de mercado para as empresas do mesmo segmento de companhias citadas. Em outras palavras, a divulgação de operações anticorrupção contribui para a redução de discrepâncias de precificação inerentes à corrupção praticada pelas empresas envolvidas nas respectivas operações. Tal ajuste de precificação pode estar associado à correção feita pelo mercado mediante os prejuízos trazidos pela concorrência desleal à competitividade.

Este estudo apresenta algumas limitações: (i) as empresas não citadas podem apresentar outros mecanismos de melhoria dos retornos, que não são possíveis de identificação a partir da base de dados utilizada; (ii) Além disso, empresas que não foram 
citadas também podem estar envolvidas em esquemas de corrupção. Nesse caso, sugere-se que outros métodos sejam utilizados para eliminar possíveis problemas de especificação, tais como um matching ou a utilização de outro tipo de evento de corrupção.

\section{REFERÊNCIAS}

Acemoglu, D., \& Verdier, T. (1998). Property rights, corruption and the allocation of talent: a general equilibrium approach. The economic journal, 108(450), 1381-1403.

Amihud, Y., \& Mendelson, H. (1988). Liquidity and asset prices: Financial management implications. Financial Management, 5-15.

Ball, R. \& Shivakumar, L. (2008). How much new information is there in earnings?. Journal of Accounting Research, 46(5), 975-1016.

Basu, K., McGavock, T., \& Zhang, B. (2013). When competition corrupts: a theoretical analysis of market structure and the incidence of corruption.

Bhandari, L. C. (1988). Debt/equity ratio and expected common stock returns: Empirical evidence. The journal of finance, 43(2), 507-528.

Blackburn, K., Bose, N., \& Haque, M. E. (2005). Public expenditures, bureaucratic corruption and economic development. Centre for Growth and Business Cycle Research Discussion Paper Series, 53(13), 417-58.

Brown, S. J. \& Warner, J. B. (1980). Measuring security price performance. Journal of financial economics, 8(3), 205-258.

Brudney, V. (1985). Corporate governance, agency costs, and the rhetoric of contract. Columbia Law Review, 1403-1444.

Chen, L. \& Zhao, X. (2006). On the relation between the market-to-book ratio, growth opportunity, and leverage ratio. Finance Research Letters, 3(4), 253-266.

Delavallade, C. (2006). Corruption and distribution of public spending in developing countries. Journal of economics and finance, 30(2), 222-239.

Ehrlich, I., \& Lui, F. T. (1999). Bureaucratic corruption and endogenous economic growth. Journal of Political Economy, 107(S6), S270-S293.

Everhart, S. S., Martinez-Vazquez, J., , J., \& McNab, R. M. (2003). Corruption, Investment, and Growth in Developing Countries. Annual Conference on Taxation and Minutes of the Annual Meeting of the National Tax Association (Vol. 96, pp. 84-90).

Fama, E. F. \& French, K. R. (1992). The cross-section of expected stock returns. the Journal of Finance, 47(2), 427-465.

Fama, E. F. \& Jensen, M. C. (1983). Agency problems and residual claims. The Journal of Law and Economics, 26(2), 327-349.

Fisman, R. \& Svensson, J. (2007). Are corruption and taxation really harmful to growth? Firm level evidence. Journal of development economics, 83(1), 63-75.

Gompers, P., Ishii, J., \& Metrick, A. (2003). Corporate governance and equity prices. The quarterly journal of economics, 118(1), 107-156. 
Hitt, M. A., Hoskisson, R. E., Johnson, R. A., \& Moesel, D. D. (1996). The market for corporate control and firm innovation. Academy of management journal, 39(5), 1084-1119.

Ionescu, L. (2014). The adverse effects of corruption on growth and development. Economics, Management and Financial Markets, 9(4), 125.

Kolari, J. W., \& Pynnönen, S. (2010). Event study testing with cross-sectional correlation of abnormal returns. The Review of financial studies, 23(11), 3996-4025.

Lambsdorff, J. G. (2003). How corruption affects productivity. Kyklos, 56(4), 457-474.

Lee, Charles M.C. and Ng, David T (2006). Corruption and International Valuation: Does Virtue Pay? Johnson School Research Paper No. 41-06.

Mauro, M. P. (1996). The Effects of Corruptionon Growth, Investment, and Government Expenditure.

Mauro, M. P. (1997). Why worry about corruption? (Vol. 6). International Monetary Fund.

McWilliams, A. \& Siegel, D. (1997). Event studies in management research: Theoretical and empirical issues. Academy of management journal, 40(3), 626-657.

Méon, P. G. \& Sekkat, K. (2005). Does corruption grease or sand the wheels of growth?. Public choice, 122(1-2), 69-97.

Méon, P. G. \& Weill, L. (2010). Is corruption an efficient grease?. World development, 38(3), 244-259.

Mo, Pak-Hung (2001). Corruption and economic growth. Journal of comparative economics, 29(1), 66-79.

Ohlson, J. A. (1995). Earnings, book values, and dividends in equity valuation. Contemporary accounting research, 11(2), 661-687.

O'Toole, C. M. \& Tarp, F. (2014). Corruption and the efficiency of capital investment in developing countries. Journal of International Development, 26(5), 567-597.

Porta, R. L., Lopez-de-Silanes, F., Shleifer, A., \& Vishny, R. W. (1998). Law and finance. Journal of political economy, 106(6), 1113-1155.

Wang, Y. \& You, J. (2012). Corruption and firm growth: Evidence from China. China Economic Review, 23(2), 415-433.

Polícia Federal. Fases da Operação Lava Jato. Recuperado em 30 julho, 2016, em http://www.pf.gov.br/imprensa/lava-jato/fases-da-operacao-lava-jato-1

BOVESPA (2016). Empresas listadas. Recuperado em 15 agosto, 2016, em http://www.bmfbovespa.com.br/pt_br/produtos/listados-a-vista-e-derivativos/rendavariavel/empresas-listadas.html 